who runs these clinics, and I'm sure that most of them are equally frustrated when they return to their practices and find the present method of organization prevents them carrying on the good work in their home towns. In this town there are at least half a dozen of my colleagues who draw a substantial sum from the local hospital board for doing clinics in other specialties than psychiatry, and, although this by no means solves all their difficulties in the organizing of the general practice, it does at any rate help to finance such organization, and indicates G.P.s can indeed do useful work in hospital as well as in general practice.

To a great extent the hospital system has managed to solve for our consultant colleagues the problems of "proper facilities, education, and time." Many of them lay down the maximum number of patients they will see at any one clinic, and their organization copes with the excess and the unexpected, seldom to the disadvantage of the patient. In general practice under the present system we can only solve these to a lesser degree. Very many of us are now not content to be on duty every hour of every day, and have rota systems with partners or colleagues. In Norwich we have, by agreement of all G.P.s, eliminated the Saturday evening surgery, but so far have not dared to eliminate the evening surgeries; however, if our surgeries were in hospital premises would it be too optimistic to expect that patients would accept having to attend the family medicine department during normal working hours, just as they at present attend the casualty or out-patient departments by taking time off work?

Is it really necessary to have in a city of 110,000 inhabitants 110 surgeries strewn about the area? In my own practice only one-third of my patients live within walking distance of my surgery, and therefore most of them could take a bus to the hospital as easily as to my surgery.

There have been several critical appraisals of the many experiments in group practice and in health centres that have been done in the past 12 years. The very limited success of these experiments are due, I think, largely to the trichotomy of the N.H.S., especially in the matter of there being three paymasters. If general practice is to be modified in the future I should think the method of payment will have to be modified; my impression is that in recent years the politicians have shown a little more tolerance to criticism of the anatomy of the sacred cow than in the past, which encourages one in looking 10 years ahead.-I am, etc.,

Norwich, Norfolk.

J. P. Carlile.

\section{Scientific Writing}

SIR,-I have just had my attention drawn to your April 13 (p. 1014) edition, in which Pertinax commented on the " mouthful" I wrote in Nature" about standards of scientific writing. Of course, Pertinax's comments are misguided (to put it mildly), but they are welcome signs of the growing concern about the weaknesses in scientific writing.

In our department we are engaged in a systematic investigation into the problems involved in communicating scientific information. Our aims are: to find out what justification there is for the growing criticism of scientific and technical writing; to analyse the special difficulties presented by scientific material ; to discover the strengths and weaknesses of scientific writing at present, and to diagnose their causes; to devise new ways of teaching and testing ability in communication in our undergraduate courses; and to provide help for industry in cases where help with communication problems is required.

We are concerned with all kinds of scientific and technical writing, whether it is by specialists for other specialists, or by specialists for non-specialists, and we are examining layout, general presentation, use of English, and use of illustrative aids.

With the co-operation of many companies and research centres, we have gathered a wide selection of the various forms of writing required in industrial, commercial, and scientific contexts (reports, abstracts, memoranda, minutes, instructions, etc.). We have gathered information about the special layout required by individual companies, and evidence of the main difficulties and weaknesses usually shown in scientific and technical writing. We have also collected opinions on what sort of preparation for scientific writing ought to be and could be included in the training of scientists and technologists.

Our discussions with scientists now in industry and research have raised many interesting points. The outstanding fault in scientific writing, it seems, is illogicality -thoughts are confused, ill-arranged, and incomplete. Verbosity, the unnecessary use of jargon, lack of vocabulary, lack of understanding of the uses of punctuation (as revealed, for example, by Pertinax), and absence of any sense of pace and weight are repeatedly criticized. Scientific writing is described as imprecise, unnecessarily ponderous, and needlessly obscure.

The suggested reasons for these faults are many and complicated: poor English teaching, mechanical cramming of scientific facts, the complexity of scientific information, the scientist's attitude to communication, time and space for writing-all these have obviously contributed to present weaknesses.

We are anxious to gather as much fact and opinion as possible before we begin a detailed analysis of our evidence next year. We should welcome co-operation from any of your readers who are conscious of difficulties in the communication of scientific information. In particular, we should be pleased to receive examples of very good or very bad scientific writing, and to hear opinions on the nature and extent of training in communication that ought to be included in the training of scientists.-I am, etc.,

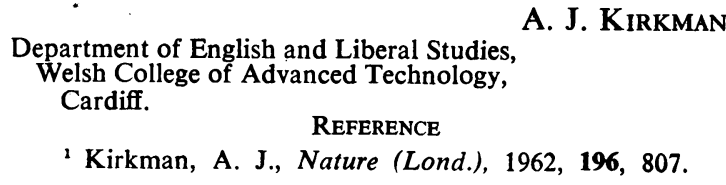

\section{Psychiatric Research}

SiR,--In the first Mental Health Research Fund Annual Lecture (April 27, p. 1107) Lord Taylor advocates greatly increased support for psychiatric research. Whilst we are in hearty agreement with his plea, the one-sided picture of psychiatric research that he paints calls for comment. Of two and a half columns of print, two concern biochemical, pharmacological, and pathological inquiries. The half-column on social factors refers only to epidemiology. Neither psychosocial studies nor purely psychological studies are mentioned. Faint praise for its humanity is used to damn psychoanalysis. 